\title{
PATTERNS IN SIZE AND SHEDDING OF FASCIOLA HEPATICA EGGS BY NATURALLY AND EXPERIMENTALLY INFECTED MURID RODENTS
}

\author{
M. Adela Valero, Miroslava Panova*, Ana M. Comes ${ }^{\star}$, Roger Fons $\dagger$, and Santiago Mas-Coma* \\ Departamento de Parasitología, Facultad de Farmacia, Universidad de Valencia, 46100 Burjassot—Valencia, Spain. e-mail: \\ madela.valero@uv.es
}

\begin{abstract}
Using samples collected on the island of Corsica, a comparative study was done of the morphometry of Fasciola hepatica eggs shed by cattle and by naturally and experimentally infected murid rodents (wild Mus musculus and Rattus rattus and Rattus norvegicus Wistar laboratory strain). Eggs shed by murids are smaller in size than those shed by naturally infected cattle. A second study analyzed the number of $F$. hepatica eggs shed in murid feces at different time intervals, i.e., months, days, and 6-hr periods, by the Kato-Katz technique. Both experimentally and naturally infected black rats $(R$. rattus) were used, and Wistar rats were experimentally infected and included for comparison. The present studies prove that black rats $R$. rattus are able to shed eggs independently from the liver fluke isolate and that egg shedding occurs throughout the life of this host species, uninterrupted during all the months analyzed in a 2-yr period. Moreover, the results suggest that this shedding is continuous, with eggs appearing in the feces daily. The results on egg shedding by wild black rats $R$. rattus reach their maximum shedding in spring and autumn and a maximum during twilight hr. These chronobiological patterns appear to favor parasite transmission, both seasonally and daily.
\end{abstract}

Fascioliasis is a disease caused by digenean trematode species belonging to the genus Fasciola, which is important from both economic and public health perpectives. In economic terms, fascioliasis is important in sheep and cattle, though a wide range of domestic animals may also be affected, e.g., members of the Bovidae, Equidae, and Camelidae. Wild mammals can also contract the disease, and some are known to act as reservoir hosts, e.g., members of the Cervidae, Marsupialia, and Lagomorpha (Boray, 1969; Mas-Coma et al., 1987, 1988). In public health terms, human fascioliasis has been reported in many parts of the world, with prevalences and intensities ranging from low to very high and with several geographical areas having been described as endemic for the disease in humans (Mas-Coma, Bargues, and Esteban, 1999; Mas-Coma, Esteban, and Bargues, 1999).

On the Mediterranean island of Corsica, fascioliasis caused by Fasciola hepatica exhibits an unusual geographical distribution, covering almost the whole of this very large, mountainous island. In Corsica, fascioliasis exhibits a high prevalence in domestic cattle and sheep (Gretillat, 1963). However, a low prevalence in humans is known (Gitard et al., 1965; Gil-Benito, Ciolkovitch et al., 1991; Gil-Benito, Mas-Coma et al., 1991). Mas-Coma et al. $(1987,1988)$ reported a transmission focus at the mouth of the river Fango, where $F$. hepatica was found in the liver of 2 wild rodent species, i.e., the house mouse Mus musculus Linnaeus, 1758, and the black rat Rattus rattus (Linnaeus, 1758).

The black rat $R$. rattus has been cited as a reservoir of several human parasites, although very few experimental studies have been performed because of the great difficulties involved in laboratory rearing and maintenance of this wild rodent species. However, Valero et al. (1998) successfully adapted Corsican black rats to the laboratory. This enabled experimental infection of intermediate lymnaeid hosts and subsequent infection of de-

Received 8 May 2000; revised 21 June 2001; accepted 22 October 2001.

* Departamento de Parasitología, Facultad de Farmacia, Universidad de Valencia, Av. Vicente Andrés Estellés s/n, 46100 Burjassot-Valencia, Spain.

$\dagger$ Laboratoire Arago, Université Pierre et Marie Curie, CNRS URA 2156, 66650 Banyuls-sur-Mer, France. finitive hosts with the black rat $F$. hepatica isolate, thus proving the viability of the black rat as a potential reservoir host.

The life cycle of $F$. hepatica occurs in alternate aquatic and terrestrial ecosystems. The eggs are shed by a definitive terrestrial host, but egg development occurs in fresh water and larval stage development then occurs in aquatic and amphibious lymnaeid snails (Mas-Coma and Bargues, 1997). To verify that the black rat potentially plays a significant role in the transmission of the disease, studies were undertaken to analyze whether the chronobiological pattern of $F$. hepatica egg shedding by black rats meets the requirements for maximum transmission success. Hence, it was necessary to confirm that shedding of eggs into water could take place both (1) in the appropriate seasons, when lymnaeid populations are still active (keeping in mind that in the Mediterranean region fascioliasis transmission is biseasonal, in spring and autumn, because of the activity periods of the intermediate snail host species Lymnaea truncatula-see Oviedo, 1992); and (2) at the appropriate time during which black rats visit aquatic habitats inhabited by lymnaeids. Moreover, the studies were used to perform a test for patterns in egg size, e.g., to phenotypically characterize the adaptation process of the liver fluke to the wild murid rodent hosts at this phase of the life cycle.

A comparative study was performed on the morphometry of $F$. hepatica eggs shed by naturally infected cattle from Corsica, the most common definitive host species on this island, and eggs shed by naturally infected murids (M. musculus and $R$. rattus) captured in Corsica, as well as by laboratory white rats of the Rattus norvegicus Wistar strain experimentally infected with a liver fluke isolate obtained from Corsican cattle.

The presence of a gall bladder favors the accumulation of parasite eggs in ruminant hosts. This phenomenon might distort studies on the chronobiology of $F$. hepatica egg release based on coprological analyses. Given that murid rodents of the genus Rattus have no gall bladder, this problem is avoided. Fasciola hepatica eggs shed by murids were used to test for patterns in the number of eggs shed over time. Both naturally and experimentally infected Corsican black rats were used for this purpose. Laboratory white rats were experimentally infected and included in the study for comparison. 
TABLE I. Experiment list indicating periods in which fecal pellets were collected, rat source, rat species analyzed (including rat code with infection source), and sampling time employed in each rat. Mo, number of months analyzed in each rat. Days, number of days analyzed in each rat. Code: rat code and source of infection ( $\mathrm{Rrn}=R$. rattus naturally infected from Corsica; Rrb $=R$. rattus experimentally infected with bovine isolate from Corsica; $\mathrm{Rrm}=R$. rattus experimentally infected with murine isolate from Corsica; $\mathrm{Rnb}=R$. norvegicus Wistar experimentally infected with bovine isolate from Corsica). Females: Rrn1, Rrn2 Rrn3 Rrn4, Rrn5, Rrn6, Rrb1, Rrb2, Rrb3, Rrm1, Rnb6, Rnb7. Males: Rrn7, Rrn8, Rrn9, Rrn10, Rrb4, Rrb5, Rrm2, Rnb8, Rnb9.

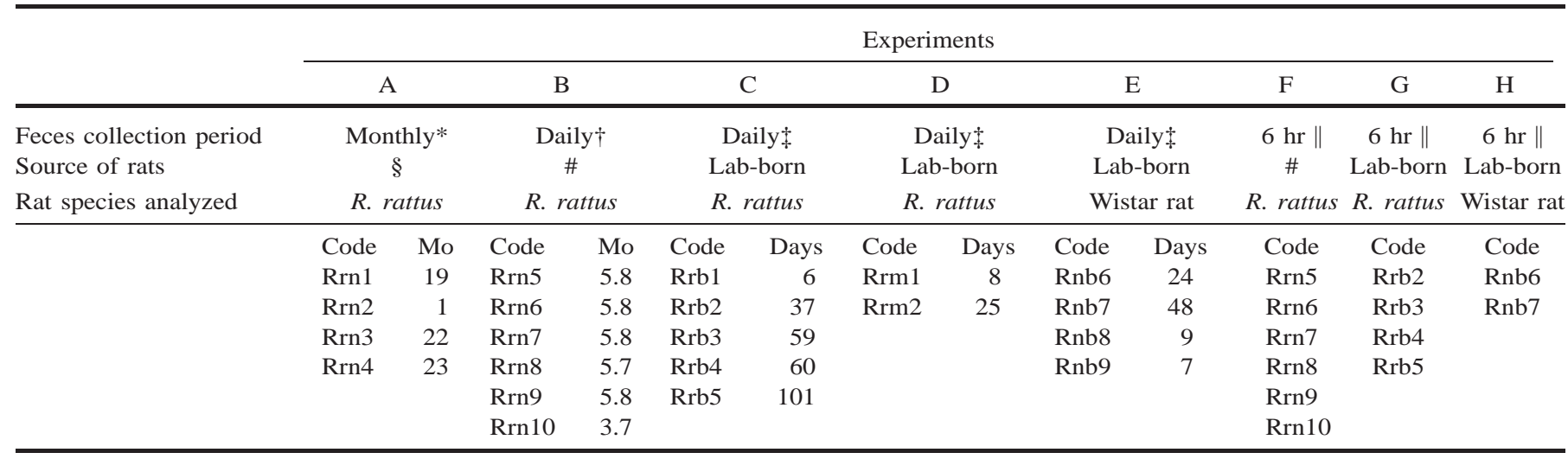

* From October 1991

$\uparrow$ From May 1993.

$\$$ From the first day of the prepatent period of each rat.

$\|$ Fecal samples were collected every $6 \mathrm{hr}(3,9,15$ and $21 \mathrm{hr}) 3$ days per week, for 3 consecutive weeks.

$\S$ Captured in October 1991.

\# Captured in March 1993

\section{MATERIALS AND METHODS}

\section{Murid host material}

Animals were housed in Micro-Isolator boxes and maintained in a pathogen-free electrically heated room, with a $12 \mathrm{hr}$ light:12 hr darkness cycle. A balanced commercial rodent diet and water were provided ad lib. The diet was supplemented with fruit. Naturally infected wild house mice and black rats and lab-reared, experimentally infected black rats and laboratory white rats were examined.

Murid rodents were captured from the mouth of the river Fango on different dates on the island of Corsica using small mammal traps set at night. All the animals captured were examined for $F$. hepatica eggs in their feces using the Kato-Katz technique (Helm-Test ${ }^{\oplus}$, AK-Indústriae Comércio, Ltda., Belo Horizonte, Minas Gerais, Brazil).

The laboratory born, experimentally infected rodents included $7 R$. rattus rats, all 8- to 14-mo-old, born from $R$. rattus wild animals captured on the island of Corsica. In addition, $4 R$. norvegicus animals of the Wistar strain (Iffa Credo, Barcelona, Spain), 2- to 3-mo-old, were also used.

\section{Experimental procedures}

Only Corsican strains of $F$. hepatica and L. truncatula were used. Lymnaea truncatula snails that shed the cercariae that gave rise to the metacercariae were from a lab-reared strain. These snails were infected (Mas-Coma et al., 2001) with miracidia from $F$. hepatica eggs recovered from the bile of naturally-infected cattle killed in the slaughterhouse of Portovecchio, Corsica (bovine isolate) and from feces of naturally infected black rats trapped in the area of the mouth of the river Fango, Corsica (murine isolate). Rats were experimentally infected with 1- to 12-day-old metacercariae obtained from experimentally infected L. truncatula and stored in freshwater at $4 \mathrm{C}$ until use. Before infecting the rats, the viability of the metacercariae was checked using the refractile appearance of the excretory granules as the criterion (Boray, 1969). Twenty $F$. hepatica metacercariae per rat were inoculated orally by means of paper pellets under controlled ether anesthesia (Panreac, Barcelona, Spain). Lab-reared black rats were experimentally infected with metacercariae from bovine and murine isolates (Table I). Wistar rats were experimentally infected with metacercariae of the bovine isolate (Table I). Positive infection was verified by detection of eggs in feces. After day 30 postinfection (dpi), fecal pellets were collected daily for this purpose. The number of worms that successfully developed in each rat was established by necropsy at the end of the study. The rats were killed using ether. Fasciola hepatica worms were collected under a dissecting microscope. Initially, the bile duct was examined for the presence of worms, though the rest of the organs and viscera were also studied under a stereomicroscope. Finally, the thoracic and abdominal viscera and cavities were thoroughly rinsed with water to assure the recovery of all worms.

\section{Egg materials}

Eggs that were included in the study came from naturally infected $M$. musculus mice (parasitized by 2 adults) and $R$. rattus rats (from 3 rats parasitized by only 1 adult each) and from Wistar rats experimentally infected with the Corsican bovine isolate ( 2 rats parasitized by 1 adult each), in all cases filtered from feces. The second source included eggs filtered from the bile of Corsican, naturally infected cattle. Length (EL) and width (EW) of the eggs were measured. The product of these 2 dimensions was used as a measure of egg size (ES) (Poulin, 1997).

\section{Egg shedding}

Fecal pellets were collected directly from the cages of each animal and kept in a closed petri dish before examination to avoid desiccation. Fecal pellets were collected monthly (Experiment A), daily (Experiments B-E), or every $6 \mathrm{hr}$ (Experiments $\mathrm{F}-\mathrm{H})$. The number of times sampled was limited by the survival of the rats under laboratory conditions. All rats were sampled at $0900 \mathrm{hr}$ for the monthly or daily groups and at $0300,0900,1500$, or $2100 \mathrm{hr}$ for the groups sampled every 6 hr. Egg detection was carried out using 3 Kato-Katz slides for the monthly group and 1 Kato-Katz slide for the daily and 6-hr groups. These groups are summarized in Table I.

\section{Calculation of the number of eggs shed}

The feces of the naturally infected wild $R$. rattus specimens (Rrn5, Rrn6, Rrn7, Rrn8, Rrn9, and Rrn10) and Wistar rats (Rnb6 and Rnb7) (see Table I) were collected for 24 consecutive days to calculate the mean weight of the feces shed by each rat species. The number of eggs per gram of feces (epg) shed by each rat was calculated using the KatoKatz technique. The egg output per fluke, per rat, and per day were calculated. 
TABLE II. Biometric measurements of $F$. hepatica eggs in house mice $M$. musculus, black rat $R$. rattus and naturally infected cattle on the island of Corsica and in laboratory white Wistar rats experimentally infected with bovine isolate from Corsica. All values are shown as range, with the mean and standard deviation (SD) in parentheses. EL, egg length $(\mu \mathrm{m})$; EW, egg width $(\mu \mathrm{m})$; ES, egg size $\left(\mu \mathrm{m}^{2}\right)$.

\begin{tabular}{lllll}
\hline & M. musculus & \multicolumn{1}{c}{ R. rattus } & \multicolumn{1}{c}{ Wistar rat } & \multicolumn{1}{c}{ Cattle } \\
\hline EL & $117-122$ & $114-148$ & $122-148$ & $125-149$ \\
& $(119 \pm 2)$ & $(133 \pm 8)$ & $(134 \pm 6)$ & $(136 \pm 9)$ \\
EW & $60-83$ & $60-74$ & $63-80$ & $68-83$ \\
& $(74 \pm 7)$ & $(67 \pm 3)$ & $(70 \pm 4)$ & $(74 \pm 6)$ \\
ES & $7,158-9,887$ & $7,148-10,344$ & $7,681-11,841$ & $9,128-11,300$ \\
& $(8,836 \pm 809)$ & $(9,011 \pm 685)$ & $(9,376 \pm 866)$ & $(10,114 \pm 801)$ \\
\hline
\end{tabular}

\section{Statistical techniques}

Data processing was carried out with Cricket and SPSS 6.1 software (Macintosh). Statistical comparison of categorical variables was carried out with the chi-square test of Fisher's exact test. Comparison between the averages of egg length, width, and size from different host species was carried out using the one-way ANOVA and a post hoc test (Scheffe). Values were considered statistically significant when $P<0.05$.

\section{RESULTS}

\section{Morphometric values of eggs}

The morphometric values of the $F$. hepatica eggs from the 4 host species studied are summarized in Table II. The ANOVA test used to separately analyze EL, EW, and ES showed significant differences in the 3 cases $(P<0.0001)$. The significant differences obtained by comparing each egg measurement in pairs of definitive host species using the Scheffe test are shown in Table III. The ES in cattle showed significant differences in all definitive host species pairs.

\section{Egg shedding}

The weight of the feces shed by rat species was $1.1-6.1 \mathrm{~g} /$ day $(\bar{x}=2.6 \mathrm{~g} /$ day $)$ in $R$. rattus and $3.6-10.65 \mathrm{~g} /$ day $(\bar{x}=5.9$ $\mathrm{g}$ /day) in Wistar rat.

Experiment A: Egg shedding in naturally infected black rats was not homogeneous over time. The data per month expressed in epg/day revealed uninterrupted shedding nearly throughout the entire life span of the black rat (Fig. 1). The shedding pattern showed alternations between high and low level sheddings. Over the 2 yr, 1 maximum egg shedding period per year was observed in the autumn months of October and November, with a second peak in the spring months.

Experiment $B$ : The data on daily shedding in naturally infected black rats are given in Table IV. Continuous shedding of eggs was observed, with alternating periods of high and low emissions. When these data are grouped by month (May-September) and expressed as percentages, in all the rat samples, there is a progressive synchronic decrease in the shedding of eggs from June to August, followed by an increase in September.

Experiments $C-E$ : In the experimentally infected black rats, in Experiment $\mathrm{C}$, the average number of eggs emitted weekly per rat increased progressively to a maximum in the 12th-13th wk of infection (Fig. 2). The data on the daily shedding in the 3 experimentally infected groups (Experiments C, D, E) are
TABLE III. Significant differences detected in F. hepatica egg measurements in pairs of definitive host species by post hoc test (Scheffe). EL, egg length; EW, egg width; ES, egg size.

\begin{tabular}{lccc}
\hline & M. musculus & R. rattus & Wistar rat \\
\hline$R$. rattus & EL, EW & & \\
Wistar rat & EL, EW & & \\
Cattle & EL, ES & EW, ES & EW, ES \\
\hline
\end{tabular}

given in Table $\mathrm{V}$. The results showed a progressive increase in epg per worm per day up to dpi 80 . Thereafter, the egg shedding was characterized by alternation between periods of high and low epg per adult. The comparison between the daily evolution of the epg per worm per day up to dpi 66 in Experiments D and $\mathrm{E}$ against experiment $\mathrm{C}$ showed no differences.

Experiments $\mathrm{F}-\mathrm{H}$ : The epg in 6-hr periods and expressed as percentages showed a maximum in Experiment $\mathrm{F}$ at $2100 \mathrm{hr}$, in Experiment $\mathrm{G}$ at $1500 \mathrm{hr}$, and in experiment $\mathrm{H}$ at $0300 \mathrm{hr}$. When these data were grouped into light (0900-2100 hr) and dark (2100-0900 hr) periods and expressed as percentages, the greatest shedding was seen in the dark period in Experiment $\mathrm{F}$ (light, 37.5\%; dark, 62.5\%). Significant differences were detected between the percentages of light-dark period emissions $\left(\chi^{2}, 23274.4 ; P=0.0001\right)$. In contrast, most eggs were shed in the light period in Experiment G (light, 65.3\%; dark, 34.7\%) and Experiment $\mathrm{H}$ (light, 54.9\%; dark, 45.1\%). Significant differences were detected between the percentages of light-dark period sheddings in both cases $\left(\chi^{2}, 190,965.4\right.$ and 19,653.4, respectively; $P=0.0001$ ).

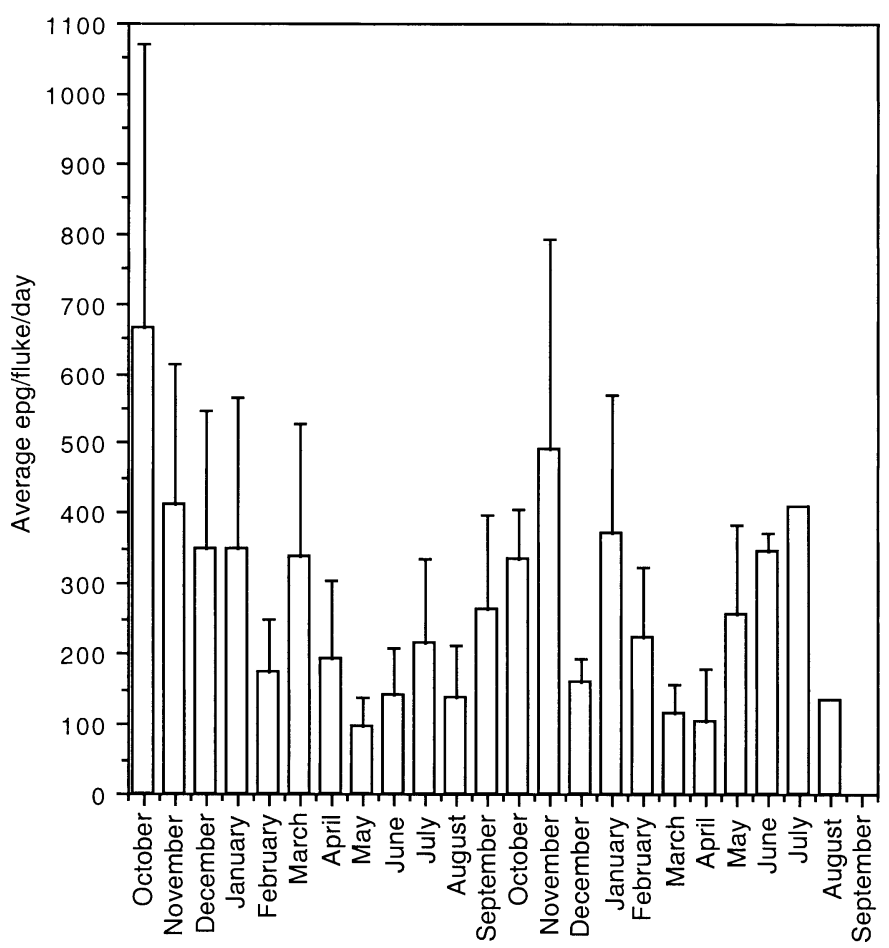

FIGURE 1. Average number of $F$. hepatica epg of feces per fluke per day shed by naturally infected wild $R$. rattus specimens during the 23 mo of the experiment. Vertical axes represent the standard error (SE). 


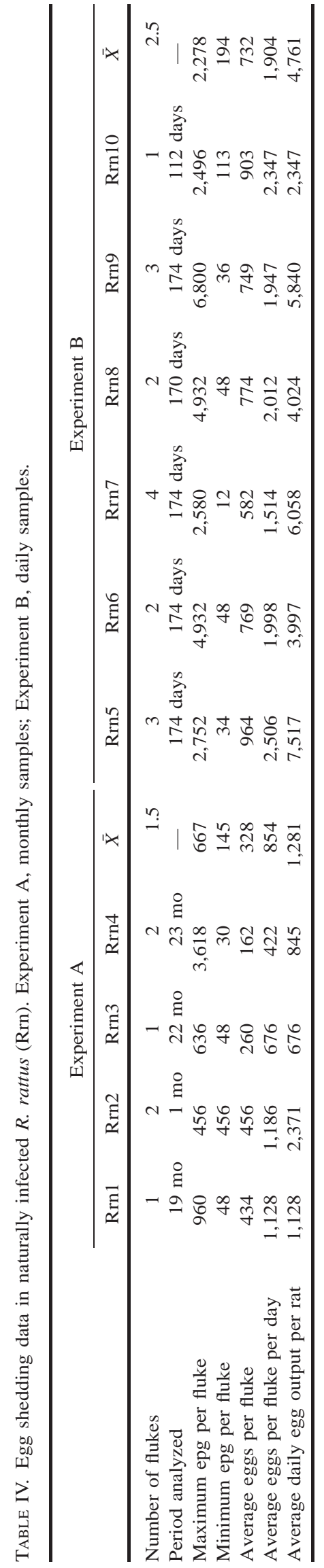

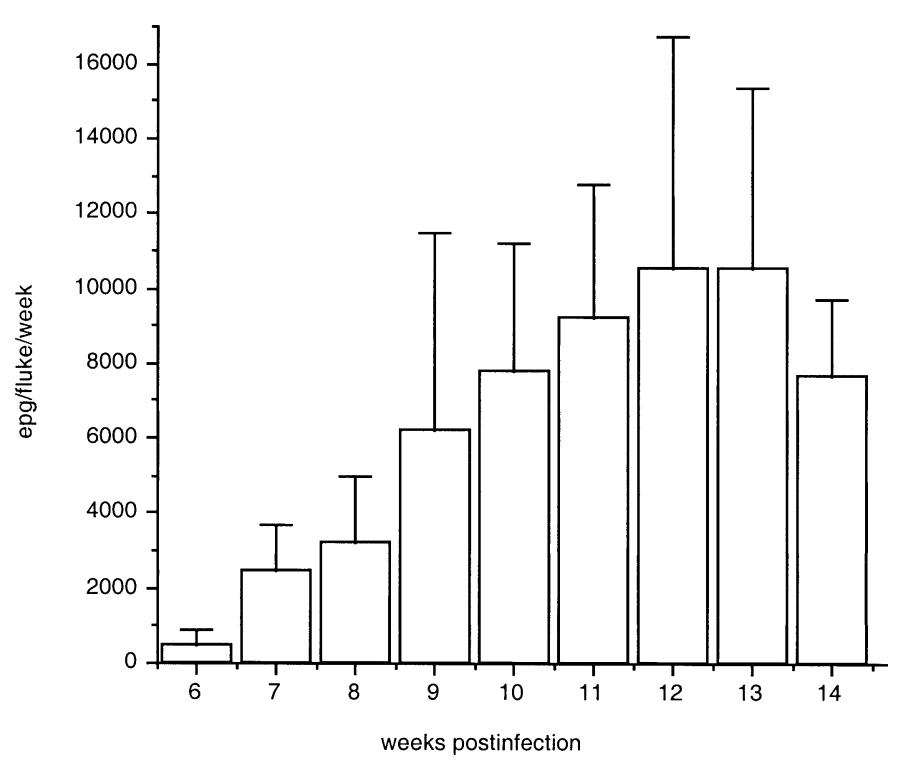

Figure 2. Average weekly shedding of $F$. hepatica epg of feces by laboratory-born $R$. rattus experimentally infected with bovine liver fluke isolate during the 100 days of the experiment. Vertical axes represent the standard error (SE).

\section{DISCUSSION}

The mean ESs for murid liver flukes were smaller than the mean ES for Corsican cattle flukes. These results indicate that $F$. hepatica egg size is influenced by the host species. As pointed out by Poulin (1997), the host mass correlates with the space available for parasites in various organs, which may place physical constraints upon trematode body size. In the present studies, small host body mass of rats and mice was in turn associated with diminished $F$. hepatica egg size.

Valero et al. (1998) have experimentally shown that the adult $F$. hepatica parasite reaches sexual maturity and produces eggs in Corsican black rats. The present studies show that the rat $R$. rattus is able to shed eggs independently from the liver fluke isolate. Egg shedding continued over a 2-yr period. Moreover, this shedding was continuous, with eggs appearing in feces daily. From the seasonal viewpoint, results show level shedding peaks in spring and autumn. From the daily point of view, egg shedding by wild $R$. rattus showed a maximum in twilight.

Egg shedding by black rats shows a lower average number of eggs per fluke per day $(850-2,150)$ than the range normally found in sheep $(8,800-25,000)$ or cattle $(10,000-12,000)$ (Boray, 1969) but much higher than the values found in rabbits (1969) (Montgomerie, 1931).

Unfortunately, there are no studies performed on the chronobiology of the egg shedding by ruminant hosts in the Mediterranean area; in continental climate areas of England and Spain, the highest egg count found in cattle was observed in winter (Whitehead, 1976; Gonzalez-Lanza et al., 1989).

Studies by Bogatko (1972) have demonstrated the existence of a maximum egg shedding in cattle between 1900 and 2000 hr. However, Düwel and Reisenleiter (1984) did not detect any correlation between epg and the time of day in the same livestock host species. This fact may be related to the egg stocking capacity of the large gall bladder in these ruminants.

These results on egg shedding by Wistar rats and laboratory- 


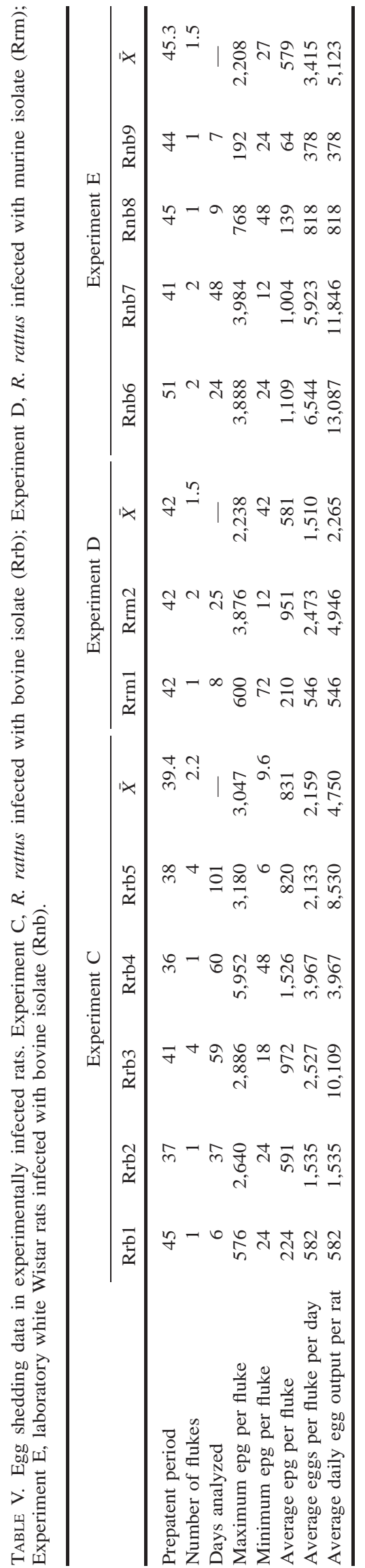

born black rats showed a maximum of level shedding in the light period of the day, suggesting an influence of laboratory adaptation. The chronobiological patterns of liver fluke egg shedding by wild black rats appear to favor the transmission, both seasonally and daily.

The average monthly temperature in Corsican coastal areas, where infected black rats were trapped, is moderate (it tends to remain above $10 \mathrm{C}$ all yr round), and rainfall reaches 2 high peaks in March and October. In the summer months of July, August, and September, evapotranspiration exceeds rainfall. This 3-mo period is characterized by extreme dryness, as is typical in the Mediterranean setting (Pomponi et al., 1984). Lymnaea truncatula populations in coastal areas of Corsica exhibit periods of inactivity (Oviedo, 1992) during the summer months. These results show minimal shedding in summer, when egg development is most difficult, and level shedding peaks in spring and autumn mo, when there is substantial rainfall and a sufficiently wet environment.

The results obtained in the black rat suggest a correlation between egg shedding and activity of the host. Thus, the wild black rat, captured in nature, retains the typical twilight-crepuscular activity that it has in its natural environment (Kahmann and Haedrich, 1957; Alcover, 1984; Cheylan, 1988). In contrast, the laboratory-born black rat adopts a diurnal activity related to human activity, similarly to the Wistar rat. The relation between maximum egg shedding and the activity of the black rat out of its nest in the field may facilitate eggs reaching the water bodies inhabited by L. truncatula.

\section{ACKNOWLEDGMENTS}

This study was supported by Projects PB92-0517-C02-01 and PB870623 of the DGICYT of the Spanish Ministry of Education and Science, Madrid, by Project PDP B2/181/125 of the WHO of Geneva, Switzerland, by French-Spanish Acciones Integradas 68/240 (Area 4), 91/89 and HF-121/90, and by the financial aid to the Valencia-Paris VI Interuniversity Agreement. Technical collaboration by J. A. Oviedo, M. D. Marcos, and C. Fayos (Valencia, Spain), and J. P. Clara (Banyuls-surMer, France) is acknowledged. This work was carried out while the second author (M.P.) was the recipient of a predoctoral fellowship from the Agencia Española de Cooperación Internacional (A.E.C.I.) of the Spanish Ministry of Foreign Affairs (Madrid, Spain).

\section{LITERATURE CITED}

Alcover, J. A. 1984. Mammals of the Pityusic Islands. In Biogeography and ecology of the Pityusic Islands, H. Kuhbier, A. J. Alcover, and C. Guerau d'Arellano Tur (eds.). Dr. W. Junk Publishers, The Hague, The Netherlands, p. 455-467.

Bogatko, W. 1972. Diagnosis of liver-fluke in cattle by faecal examination. Medycyna Weterynayjna 28: 31-33.

Boray, J. C. 1969. Experimental fascioliasis in Australia. Advances in Parasitology 8: 95-210.

Cheylan, G. 1988. Les adaptations écologiques de Rattus rattus à la survie dans les îlots méditerranéens (Provence et Corse). Bulletin de Ecologie 19: 417-426.

Düwel, D., AND R. ReISENLEITER. 1984. Fasciola hepatica: Coproscopic diagnosis compared with the worm burden in the sheep. Helminthologia 21: 151-159.

Gil-Benito, A., A. Ciolkovitch, S. Mas-Coma, And M. Quilici. 1991. Enquête sur la Distomatose à Fasciola hepatica en Corse. Méditerranée Médicale 403: 21-25.

- S. Mas-Coma, M. Quilici, And A. Ciolkovitch. 1991. Focos de transmisión de Fasciola hepatica en Córcega: Distintos tipos y sus relaciones con la Fasciolosis humana durante el periodo 19841990. In Parasitología en el Sud-Oeste de Europa, S. Mas-Coma, 
J. G. Esteban, M. D. Bargues, M. A. Valero, and M. T. GalánPuchades (eds.). Aguilar S.L., Valencia, Spain, 314 p.

Gitard, R., P. Coquilhat, V. Silicany, B. Blanc, and R. M. Nicoli. 1965. La Distomatose humaine à Fasciola hepatica Linnaeus, 1758 en Corse. Bulletin de la Societé de Pathologie Exothique 3: 471474.

Gonzalez-Lanza, C., Y. Manga-Gonzalez, P. Del-Pozo-Carnero, and R. HidAlgo-ArgüEllo. 1989. Dynamics of elimination of the eggs of Fasciola hepatica (Trematoda, Digenea) in the faeces of cattle in the Porma basin, Spain. Veterinary Parasitology 34: 35-43.

Gretillat, S. 1963. Epidémiologie de certaines affections à Trématodes des animaux domestiques en Corse (Bilharziose bovine et Distomatose bovine et ovine). Annales de Parasitologie Humaine et Comparée 38: 471-481.

KahmanN, H., AND B. Haedrich. 1957. Eine Untersuchung an Rattus rattus Linnaeus, 1758 (Mamm., Rod.) auf der Insel Korsika. Zoologischer Anzeiger 158: 233-257.

Mas-Coma, S., AND M. D. BARgues. 1997. Human liver flukes: A review. Research and Reviews in Parasitology 57: 145-218. AND J. G. Esteban. 1999. Human fasciolosis. In Fasciolosis, J. P. Dalton (ed.). CAB International Publishing, Wallingford, U.K., p. 411-434.

, J. G. Esteban, And M. D. Bargues. 1999. Epidemiology of human fascioliasis: A review and proposed new classification. Bulletin of the World Health Organization 77: 340-346.

, R. Fons, C. Feliu, M. D. Bargues, M. A. Valero, and M. T. Galan-PuChades. 1987. Conséquences des phènomènes liés à l'insularité dans les maladies parasitaires. La Grande douve du foie
(Fasciola hepatica) et les Muridés en Corse. Bulletin de la Société Neuchâteloise des Sciences Naturelles 110: 57-62.

$\longrightarrow, \overline{\text {, }}, \overline{\text { AND }}-\overline{\text {. 1988. Small }}$ hepatica Linnaeus, 1758 (Trematoda: Fasciolidae): A review and two new records of epidemiologic interest on the island of Corsica. Rivista di Parassitologia 5: 73-78.

, I. R. FunAtsu, and M. D. BARgues. 2001. Fasciola hepatica and lymnaeid snails occurring at very high altitude in South America. Parasitology 123: S115-S127.

Montgomerie, R. F. 1931. On the longevity of Fasciola hepatica in experimentally infected rabbits. Journal of Helminthology 9: 209 212.

Oviedo, J. A. 1992. Contribución al estudio del ciclo biológico de Fasciola hepatica (Linnaeus, 1758) (Trematoda: Fasciolidae) a nivel de molusco hospedador intermediario en la isla de Córcega (Francia). Ph.D. Thesis. University of Valencia, Valencia, Spain, 336 p.

Pomponi, F., F. Ettori, G. Ravis-Giordani, R. Pecoueux-Barboni, P. Simi, AND J. RenuCCI (EDS.). 1984. Corse. Ecologie, economie, art, littérature, langue, historie, traditions populaires. Christine Bonneton, Artigues-près-Bordeaux, France, 363 p.

Poulin, R. 1997. Egg production in adult trematodes: Adaptation or constraint? Parasitology 11: 195-204.

Valero, M. A., M. D. Marcos, R. Fons, and S. Mas-Coma. 1998. Fasciola hepatica development in experimentally infected black rat, Rattus rattus. Parasitology Research 84: 188-194.

WhiteHEAD, J. D. 1976. Observations on the repeated treatment for fasciolosis of stock on a farm in south-west England. Veterinary Record 98: 5-9. 